\title{
Ultrasonication during the Synthesis of Manganese Oxides for Electrochemical Capacitors
}

\author{
B. C. Jones, ${ }^{a}$ A. F. Hollenkamp," and S. W. Donne ${ }^{a, *, z}$ \\ ${ }^{a}$ Discipline of Chemistry; University of Newcastle, Callaghan, New South Wales 2308, Australia \\ ${ }^{b}$ Energy Technology; Commonwealth Scientific and Industrial Research Organization, Clayton South, \\ Victoria 3J69, Australia
}

\begin{abstract}
An investigation has been conducted to examine the effect that ultrasonication has on the synthesis of manganese dioxide used as a pseudocapacitive electrode material in supercapacitors. Using the reaction between $\mathrm{KMnO}_{4}$ and $\mathrm{MnSO}_{4}$, the layered birnessite polymorph of manganese dioxide was produced with and without ultrasonication (control). X-ray diffraction analysis of the materials indicates that ultrasonication has a minimal effect on the crystallite size, although the crystallite dimensions are small anyway (8.6 vs $14.1 \mathrm{~nm}$ within the layers, and $9.4 \mathrm{vs} 8.9 \mathrm{~nm}$ between the layers for the control and ultrasonicated samples, respectively). However, ultrasonication has had a profound effect on .morphology, essentially fusing these small crystallites together to form much larger needles $100-200 \mathrm{~nm}$ in length. This fusion process has also dramatically decreased the Brunauer, Emmett, and Teller surface area (from 170 to $10 \mathrm{~m}^{2} / \mathrm{g}$ with ultrasonication), and furthermore electrochemical performance has also been diminished, although by not as much as the drop in surface area; e.g., $106 \mathrm{vs} 64 \mathrm{~F} / \mathrm{g}$. These phenomena are discussed in terms of the pore volume available for charge storage.

(1) 2010 The Electrochemical Society. [DOI: 10.1149/1.3314348] All rights reserved.
\end{abstract}

Manuscript submitted August 7, 2009; revised manuscript received December 21, 2009. Published March 16, 2010.

\section{Energy Production and Supply}

Modern society is very dependent on electrical energy. From homes to heavy industries, electricity can be found powering a range of different devices. The electrical energy for these systems most often originates from fossil fuel (coal, oil, and natural gas) burning power stations, which unfortunately are major contributors to environmental greenhouse gas emissions. Recently, considerable effort has been expended in the development and expansion of more renewable forms of energy generation, such as hydroelectric, solar, geothermal, wind, and biomass. However, with current technologies, none of these more renewable sources of energy has the realistic ability to economically substitute for fossil fuel based power. ${ }^{1}$ Therefore, energy production in the future is anticipated to be more distributed and intermittent in nature to capitalize on these smallerscale, more renewable forms of energy.

\section{Energy Storage}

With energy production heading in such a direction, the importance of energy storage also grows for load-leveling applications, as well as a means to improve efficiency. Roughly speaking, the sun does not always shine, nor does the wind always blow, and so energy storage is necessary to provide continuous power in times when direct energy production is not possible. Various energy storage options exist, particularly when stored as chemical energy, in which case batteries, supercapacitors, and fuel cells are the alternatives. Mechanical or thermal energy storage is a possibility; however, this is low grade energy, as opposed to electrochemical energy storage, which is high grade electrical energy. ${ }^{1}$

The relative merits of batteries, supercapacitors, and fuel cells can be summarized by a Ragone diagram, ${ }^{2}$ a general example of which is shown in Fig. $1 .^{3}$ In summary, fuel cells provide the highest energy density at the expense of power density, while the performance of supercapacitors is essentially the opposite. Batteries generally occupy an intermediate region within the Ragone plot, providing higher energy density compared to supercapacitors and greater power density compared to fuel cells. Extensive research is ongoing globally to boost the performance of each power source, as well as to identify what their preferred applications are. The focus of this research can be categorized as being either advanced material

\footnotetext{
* Electrochemical Society Active Member.
}

${ }^{2}$ E-mail: scott.donne (a) newcastle.edu.au development (as is the case with this work) or system development through the construction of more efficient, higher performance devices.

\section{Supercapacitor Systems}

The underlying basis of this research is on boosting supercapacitor electrode performance by improving their energy density, thus making them more broadly applicable as power sources. Commercially available supercapacitors are symmetrical devices (identical electrodes) employing activated carbon electrodes with either aqueous (e.g., $\mathrm{H}_{2} \mathrm{SO}_{4}$ ) or nonaqueous (e.g., tetraalkylammonium tetrafluoroborate in acetonitrile) based electrolytes. "The performance of these devices is quite good, with high power density and long cycle life; however, as mentioned, their energy density is limited. A strategy for improving supercapacitor energy density is to incorporate a pseudocapacitive electrode; ${ }^{5}$ i.e., an electrode that can store charge in the double layer, as a conventional supercapacitor electrode would do, as well as undergo fast reversible surface redox reactions. These types of electrodes have an enhanced capacity compared to carbon based electrodes as a result of the faradaic contribution, as well as a higher density, meaning that their volumetric energy density is also enhanced.

The prototypical supercapacitor electrode material is amorphous hydrated ruthenium dioxide $\left(\mathrm{RuO}_{2} \cdot \mathrm{xH}_{2} \mathrm{O}\right)$, which has been reported to have a capacitance exceeding $900 \mathrm{~F} / \mathrm{g}$ in an aqueous $\mathrm{H}_{2} \mathrm{SO}_{4}$ electrolyte. ${ }^{6}$ What primarily limits the commercial implementation of this material is its cost, which has prompted the search for suitable alternatives with similar behaviors. Alternative systems based on other metal oxides and conductive polymers have been reported in the literature to behave similarly; however, of these, metal oxides are preferred because of their higher energy density. ${ }^{5,6}$.Vithin the category of metal oxides, systems based on manganese dioxide are presently receiving considerable attention from the scientific community. ${ }^{7}$ With a myriad of available synthesis methods, ${ }^{8}$ and as a result of wide ranging morphologies, coupled with good faradaic electrochemical performance, low cost, and environmental friendliness, this class of materials represents an interesting and promising area of research.

\section{The Use of Ultrasonication}

Because the use of ultrasonication in material synthesis is not common, it is prudent at this time to present a brief review of its applications. ${ }^{9}$ For many years, the most significant use of ultrasonication in the laboratory has been as a means of cleaning glassware and other experimental apparatus. It was not until relatively recently 


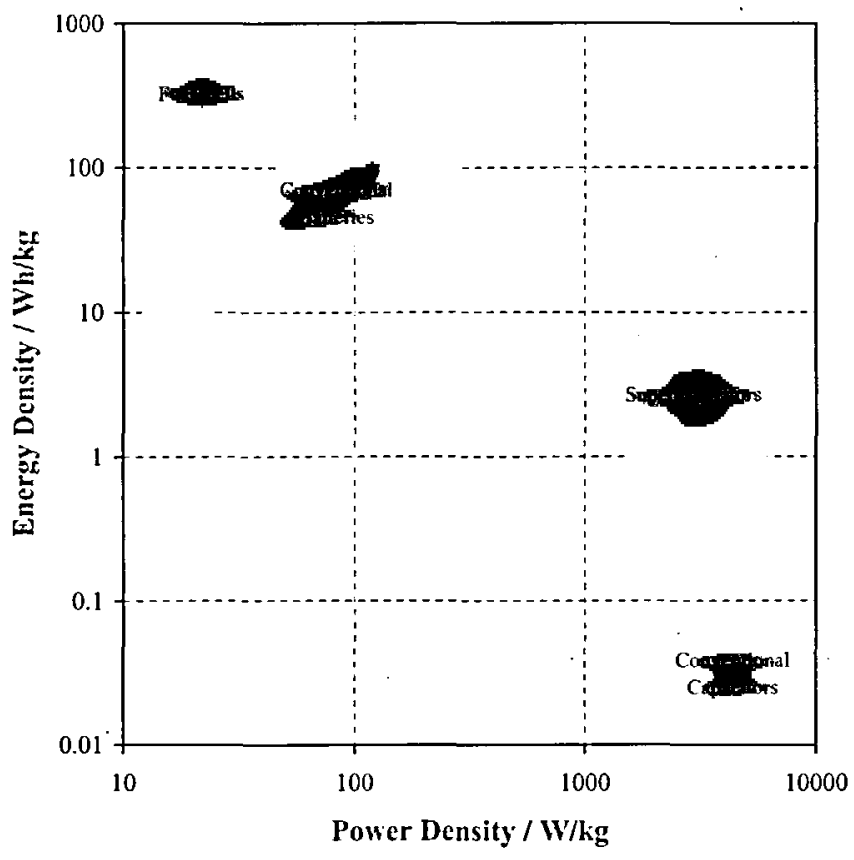

Figure 1. Ragone plot for various energy storage devices. ${ }^{3}$

that ultrasonication (or sonochemistry) was developed as a means for facilitating chemical reactions. Previously, synthetic chemists would have resorted to changes in temperature, pressure, light irradiation, or a catalyst to increase chemical reactivity. However, if you consider what is involved with the transmission of a sound wave through a medium, it is surprising that the development of sonochemistry had not happened earlier.

During the initial development of sonochemistry, ultrasonication was used in synthesis as a means of initiating or activating the most sluggish chemical reactions. Since then, the applications for sonochemistry have grown considerably in parallel with the fundamental development of acoustic cavitation, the principle underpinning this physical phenomena. ${ }^{10-12}$ When a sound wave is applied to a liquid medium, the compression and rarefaction stages of the wave induce different phenomena during transmission (Fig. 2). During the rarefaction part of the cycle, if sufficient negative pressure is applied, then the average distance between the molecules exceeds the critical molecular distance within the liquid, hence causing a cavity (or bubble) to form. In the subsequent compression half-cycle, the previously formed bubble collapses, resulting in the release of significant energy, which is available to the system at the molecular level. The way in which this energy is used depends very much on the system.

1. Homogeneous liquid phase: In this situation (Fig. 3a), the cavity would almost certainly contain vapor from the liquid medium or dissolved volatile reagents. On bubble collapse, these vapors are

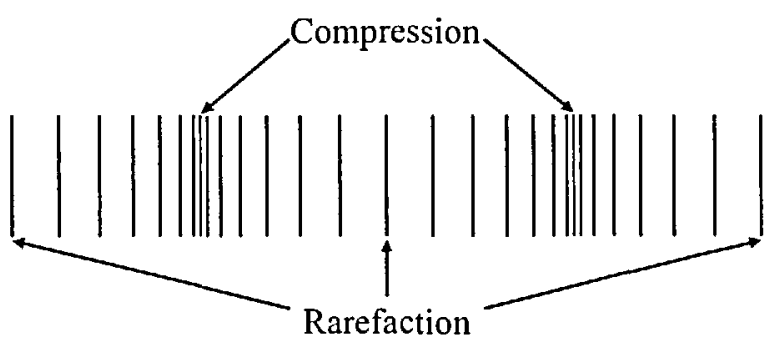

Figure 2. Compression and rarefaction cycles as a sound wave moves through a medium. (a)

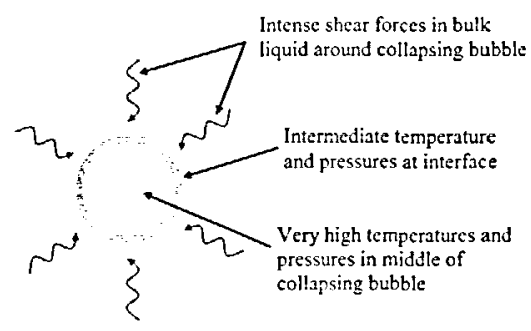

(b)

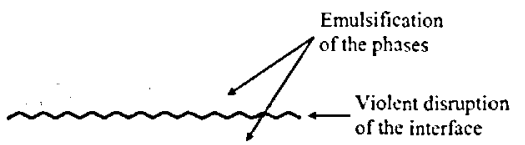

(c)

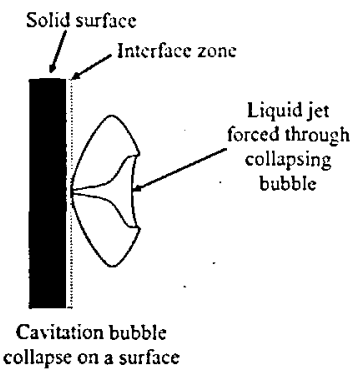

(d)
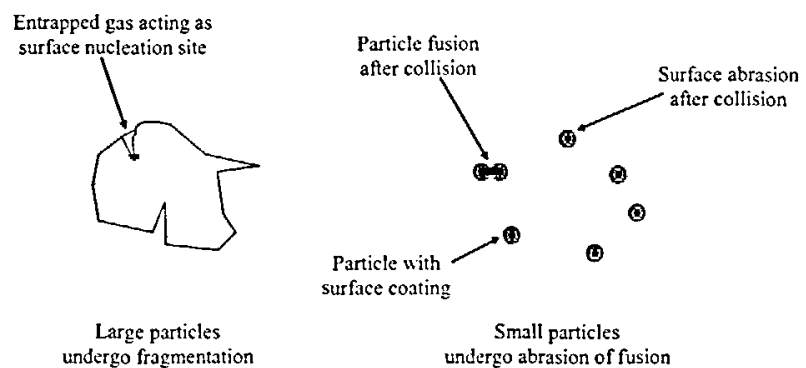

Figure 3. Cavitation effects in various systems. (a) Homogeneous liquid system, (b) heterogeneous liquid-liquid system, (c) heterogeneous solidliquid system, and (d) heterogeneous solid-liquid system of suspended particles.

subjected to extremely large increases in temperature and pressure as a result of molecular fragmentation, with generation of highly reactive radical species. For a chemical species to experience the extreme conditions generated inside the cavitation bubble during collapse, it must be in the vapor phase within the bubble. The sudden bubble collapse also results in the inrush of liquid to fill the void. So powerful is this inrush that it produces shear forces in the surrounding bulk liquid that have been shown to be capable of breaking chemical bonds in several dissolved polymeric materials. ${ }^{13,14}$

2. Heterogeneous liquid-liquid systems: Cavitation in heterogeneous media represents the systems most studied in sonochemistry. When cavitation bubbles are produced at such a phase boundary, they are strongly deformed (Fig. $3 \mathrm{~b}$ ). A liquid jet propagates across the bubble toward the interface at a velocity estimated to be hundreds of meters per second. ${ }^{9}$ At a liquid-liquid interface, the intense movement results in an injection of droplets from one liquid into the other to form an emulsion. Such emulsions are smaller in size and more stable than those obtained conventionally and often require little or no surfactant to maintain stability. ${ }^{9}$

3. Heterogeneous solid-liquid systems: At the interface in these 
systems, the evolution of cavitation bubbles has been observed to form a "jet" of liquid impinging upon the surface (Fig. 3c). ${ }^{15}$ Here, the shock on the surface produces erosion at and around the point of jet impact. Any particles ejected from the surface may react more efficiently than the bulk solid surface due to an increased surface area. When a passivating coating is present on the solid surface the jetting would "clean" the surface and activation results. ${ }^{16}$ At the same time, the surface is disorganized; local defects, dislocations, and vacancies are produced, and this can also have a positive effect on reactivity. ${ }^{9}$ Furthermore, local temperature increases as a result of cavitation and may influence the crystal structure of the solid phase, either through direct nucleation or recrystallization. Associated with bubble collapse is the increase in mass transfer to the surface by the disruption of the interfacial boundary layers. In the case of solid interfaces based on coarse powders, cavitation collapse can produce enough energy to cause fragmentation and activation through surface area increase. For very fine powders, the particles are accelerated to a high velocity by cavitational collapse and may collide to cause surface abrasion. ${ }^{9}$ For some powders, these collisions generate sufficient heat to cause particle fusion (Fig. 3d). ${ }^{9}$

\section{This Work}

What we report here is our work which focused on manipulating the morphology of manganese dioxide during its synthesis through the use of ultrasonication, which is known as a means of enhancing reaction rates and breaking up larger particles. ${ }^{9}$ The intent is to first examine the fundamental changes in manganese dioxide physicochemical properties that result from ultrasonication during synthesis, as well as to potentially develop an enhanced supercapacitor electrode material.

\section{Experimental}

Sample preparation.- Manganese dioxide samples were prepared via the reaction between $\mathrm{KMnO}_{4}$ (Sigma-Aldrich) and $\mathrm{MnSO}_{4} \cdot \mathrm{H}_{2} \mathrm{O}$ (Sigma-Aldrich), i.e.

$$
2 \mathrm{MnO}_{4}^{-}+3 \mathrm{Mn}^{2+}+2 \mathrm{H}_{2} \mathrm{O} \rightarrow 5 \mathrm{MnO}_{2}+4 \mathrm{H}^{+}
$$

$\mathrm{KMnO}_{4}(2.00 \mathrm{~g}, 0.013 \mathrm{~mol})$ was dissolved into $100 \mathrm{~mL}$ of Milli-Q ultrapure water in a $500 \mathrm{~mL}$ beaker. This was then clamped into place in an ultrasonic bath (Ultrasonics Australia DCT-9, $200 \mathrm{~W}, 40$ $\mathrm{kHz}$ ) such that the water level in the bath was well above the solution level within the beaker. A peristaltic pump was set up to recirculate the water in the ultrasonic bath with a reservoir of ambient temperature water $\left(22 \pm 1^{\circ} \mathrm{C}\right)$ so as to maintain a constant temperature throughout the experiment because ultrasonication increases the temperature of the bath water. A separate solution of $\mathrm{Mn}^{2+}$ was prepared by dissolving $3.209 \mathrm{~g}$ of $\mathrm{MnSO}_{4} \cdot \mathrm{H}_{2} \mathrm{O}(0.019 \mathrm{~mol})$ into another $100 \mathrm{~mL}$ of Milli-Q ultrapure water. With the ultrasonic bath and the recirculating water switched on, this solution of $\mathrm{Mn}^{2+}$ was added dropwise with a burette (over the course of $1 \mathrm{~h}$ ) to the $\mathrm{MnO}_{4}^{-}$ solution in the ultrasonic bath. Ultrasonication was continued for another hour after complete addition of the $\mathrm{Mn}^{2+}$ solution. Any solids formed were collected by filtration and then subjected to a washing sequence designed to retain the pore structure in the solid by minimizing the surface tension at the solid-liquid interface when drying takes place. ${ }^{17}$ This involved first washing the solid thoroughly on the filter paper with Milli-Q ultrapure water (surface tension of $72.75 \mathrm{mN} / \mathrm{m}$ at $20^{\circ} \mathrm{C}{ }^{18}$ ) until the filtrate was the same $\mathrm{pH}$ as the wash water. The solid was then resuspended in acetone (surface tension of $23.70 \mathrm{mN} / \mathrm{m}$ at $20^{\circ} \mathrm{C}{ }^{18}$ ) for $1 \mathrm{~h}$ to extract water from the pores. The suspension was then filtered, and the resuspension process repeated this time with liquid hexane (surface tension of 18.43 $\mathrm{mN} / \mathrm{m}$ at $20^{\circ} \mathrm{C}^{18}$ ). After this third washing, the suspension was filtered with the collected solid dried in air at $50^{\circ} \mathrm{C}$. A control sample was prepared using a similar approach except without ultrasonication.

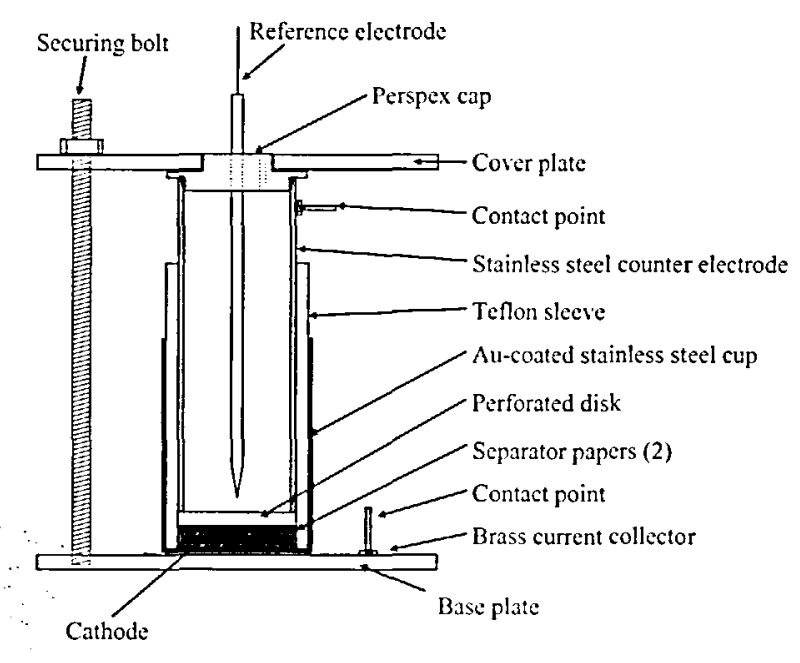

Figure 4. Cell used for electrochemical performance evaluation.

Physical and morphological characterization.-The material structure was determined by X-ray diffraction (XRD) using a Philips 1710 diffractometer equipped with a $\mathrm{Cu} \mathrm{K} \alpha$ radiation source $(\lambda$ $=1.5418 \AA$ ) operating at $40 \mathrm{kV}$ and $30 \mathrm{~mA}$. The scan range was from $10-90^{\circ} 2 \theta$ with a step size of $0.1^{\circ}$ and a count time of $2.5 \mathrm{~s}$.

Morphology was evaluated using a Philips XL30 scanning electron microscope (SEM) at a range of magnifications and a JEOL JEM-1200EXII transmission electron microscope (TEM) again at a range of magnifications, as well as by gas adsorption to determine material porosity. In this latter case, a Micromeritics ASAP 2020 surface area and porosity analyzer was used, with the samples being degassed under vacuum at $110^{\circ} \mathrm{C}$ for $6 \mathrm{~h}$ before an analysis using $\mathrm{N}_{2}$ as the adsorbate at $77 \mathrm{~K}$. The specific surface area was extracted from the gas adsorption data using the Brunauer, Emmett, and Teller (BET) isotherm, ${ }^{19}$ while the pore size distribution was determined using a density functional theory based approach (Micromeritics DFTPlus V2.00). ${ }^{20}$

Electrode preparation.-Electrodes were prepared from a blackmix consisting of a 10:1 mixture of Timcal SFG6 graphite and a manganese dioxide sample that had been moistened to form a paste with the addition of an extra $10 \%$ (by weight) of electrolyte $(9 \mathrm{M}$ $\mathrm{KOH})$. Once made, this blackmix was stored in an airtight container for at least $24 \mathrm{~h}$ to ensure adequate penetration of the electrolyte into the manganese dioxide pores. The amount of blackmix corresponding to $10 \mathrm{mg}$ of the manganese dioxide sample was then placed into the base of a Teflon-lined, Au-coated stainless steel cup $(13 \mathrm{~mm}$ radius), covered with two layers of separator paper, and then compacted under 1 tonne (for $1 \mathrm{~min}$ ) using a stainless steel piston. After this time, the compaction pressure was released and the piston was removed, leaving behind a compacted composite electrode $\sim 150 \mu \mathrm{m}$ thick. This was then covered with a perforated Perspex disk with a stainless steel sleeve inserted into a cell to retain the Perspex disk in place, as well a function as the counter electrode. The entire cell assembly was then held together by a frame consisting of a base- and cover-plate connected by three securing bolts, which were tightened to a torque of $0.75 \mathrm{~N} \mathrm{~m}$ to ensure a uniform pressure on the electrode during electrochemical cycling. Approximately $10 \mathrm{~mL}$ of electrolyte $(9 \mathrm{M} \mathrm{KOH})$ was added to the cell, as was a $\mathrm{Hg} / \mathrm{HgO}$ reference electrode. All potentials reported in this work are with respect to this reference electrode. The cell in this state was allowed to rest for $1 \mathrm{~h}$ before electrochemical cycling to ensure adequate penetration of the electrolyte into the electrode. A schematic of the electrochemical cell is shown in Fig. 4.

Electrochemical protocol.- The performance of our electrode materials was evaluated using cycling voltammetry at rates of 5,25 , and $50 \mathrm{mV} / \mathrm{s}$ for at least 100 cycles. The voltage window considered 


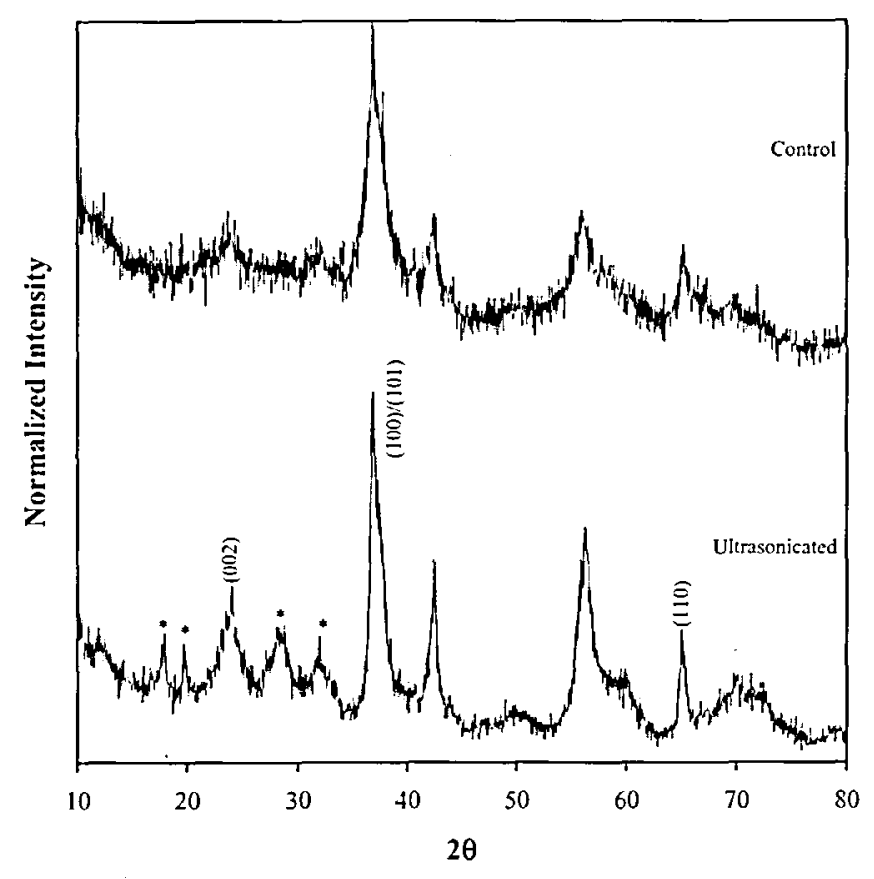

Figure 5. XRD patterns of the samples produced in this work. $\left({ }^{*}\right)$ indicates peaks from a phase other than birnessite.

in this electrolyte was from +0.4 to $-0.4 \mathrm{~V}$ vs $\mathrm{Hg} / \mathrm{HgO}$. These experiments were conducted using an EG\&G Princeton Applied Research M362 scanning potentiostat connected with LabView data acquisition software.

\section{Results and Discussion}

Material structure.-Figure 5 contains the XRD patterns from the materials produced in this work. Essentially, the manganese dioxide phase birnessite predominated irrespective of whether ultrasonication was used. There is some evidence for other phases in the pattern of the ultrasonicated sample (labeled with ${ }^{*}$ in Fig. 5). These have been identified as either $\alpha-\mathrm{MnO}_{2}$ (cryptomelane) or $\beta-\mathrm{MnO}_{2}$ (pyrolusite). The presence of these impurity phases was in some ways to be expected, particularly given the templating effect of $\mathrm{K}^{+}$ ions in the formation of birnessite and $\alpha-\mathrm{MnO}_{2},{ }^{21}$ and the fact that $\beta-\mathrm{MnO}_{2}$ is the thermodynamically stable variety of manganese dioxide $^{22}$ formed hydrothermally at elevated temperatures, which may have been induced with ultrasonication.

Birnessite possesses a layered structure, as shown in Fig. $6 a^{23}$ with foreign metal ions and water in the interlayer region. Crystallographically, it has been reported to have a wide range of symmetries, including hexagonal $\left(a_{0}=5.82 \AA\right.$ and $c_{0}=14.62 \AA{ }^{24} a_{0}$ $=2.84 \AA$ and $\left.c_{0}=7.27 \AA 25\right)$, orthorhombic $\left(a_{0}=8.54 \AA, b_{0}\right.$ $=15.39 \AA$, and $\left.c_{0}=14.26 \AA{ }^{26}\right)$, and monoclinic $\left(a_{0}=5.149 \AA\right.$, $b_{0}=2.843 \AA, c_{0}=7.176 \AA$, and $\beta=100.76^{\circ} 27$, which is a reflection of the level of disorder that can be induced in this structure. In this study, we have successfully indexed our patterns using a hexagonal unit cell with dimensions $a_{0}=2.86 \AA$ and $c_{0}=7.32 \AA$ for the control material and $a_{0}=2.87 \AA$ and $c_{0}=7.28 \AA$ for the ultrasonicated sample. This indicates a larger interlayer spacing for the control material, potentially as a result of the inclusion of more $\mathrm{K}^{+}$ions, or more likely the greater degree of disorder within the control material structure. To quantify this, the Scherrer equation ${ }^{28}$ has been used to calculate crystallite sizes. For the 100/101 peaks at $\sim 37^{\circ} 20$, which essentially represents crystallinity within the layers, the crystallite size for the control material was $8.6 \mathrm{~nm}$ compared to $14.1 \mathrm{~nm}$ for the ultrasonicated material. For the 002 peak at $\sim 24^{\circ} 2 \theta$, which represents the crystallinity between the layers, the crystallite size was $9.4 \mathrm{~nm}$ for the control material and $8.9 \mathrm{~nm}$ for (a)

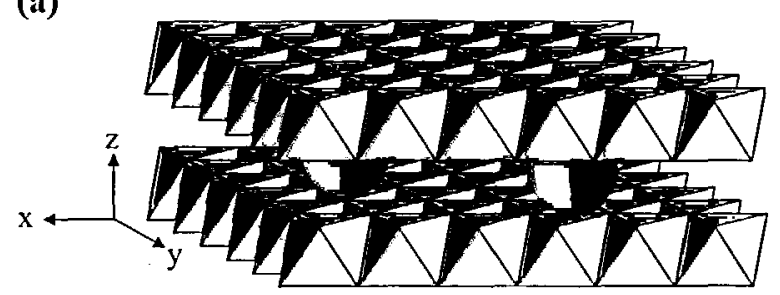

(b)

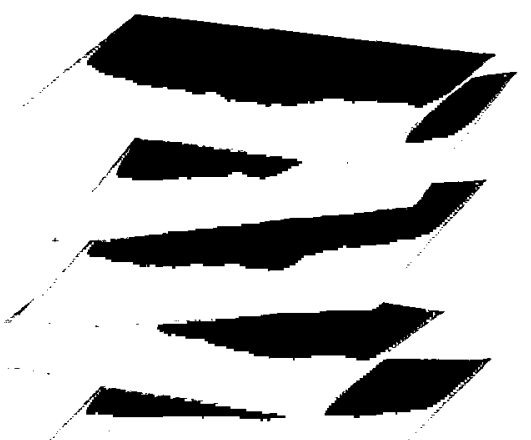

Figure 6. (a) Structure of birnessite showing interlayer water and foreign cations. (b) Schematic of the turbostratic disorder of the birnessite structure in the c-direction.

the ultrasonicated material. Therefore, while the crystallite size between the layers is relatively constant, ultrasonication appears to have a slight effect on crystallization within the layers. Overall, these crystallite sizes are quite small, indicating a very disordered material, one that is potentially suitable for use in a supercapacitor electrode. The level of disorder is particularly pronounced between the layers, most likely due to the turbostratic nature of the layered material, and manganese dioxide in particular (Fig. 6b). ${ }^{29}$

Morphology:- Representative micrographs of the control and ultrasonicated manganese dioxide samples are shown in Fig. $7 \mathrm{a}$ and b. From a broad perspective, these materials apparently have quite similar morphologies, i.e., relatively large agglomerates 5-20 $\mu \mathrm{m}$ in size composed of much smaller particles. However, upon closer inspection, the morphology of these smaller particles that comprise the larger agglomerates is quite different depending on their synthesis. The smaller particles of the control material appear to be relatively spherical, whereas those of the ultrasonicated sample appear to be needlelike. This was confirmed by TEM imaging, as shown in Fig. 8a and b. From these figures, the control material is clearly based mainly on small, "fluffy," almost amorphous particles that we would estimate to be $<10 \mathrm{~nm}$. There are also some small needles present $\sim 10 \mathrm{~nm}$ wide and up to $100 \mathrm{~nm}$ long, but these represent only a minor component of the material. For the ultrasonicated material, however, the ncedle morphology constitutes the major phase present. The needles here are also slightly larger, being $\sim 10 \mathrm{~nm}$ wide but $100-200 \mathrm{~nm}$ long.

From the XRD data shown in Fig. 5, we calculated that there were some small differences apparent in the crystallite size of these two materials. However, from the TEM images presented in Fig. 8, apparently there are substantial differences in morphology, with the ultrasonicated material apparently more crystalline than the control material. The only logical explanation for these observations is that the larger needles present in the ultrasonicated material are, in fact, agglomerates themselves, consisting of $\sim 10 \mathrm{~nm}$ primary particles fused together to form a much larger needlelike morphology. It would therefore seem that the original premise of this work, which was to use ultrasonication to break up larger particles, has in fact led to the formation of larger agglomerates as a result of the fusion of smaller particles. There is the possibility that the impurity (minor) 


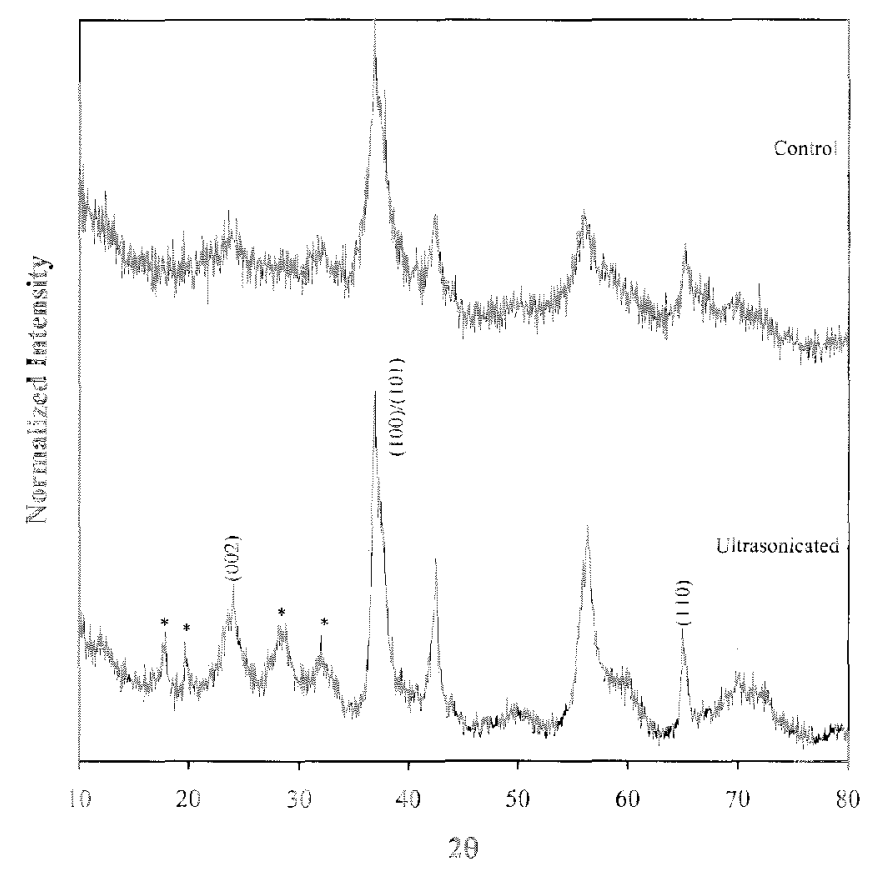

Tingre 3. XRD patterns of the sanples produced in this work. (*) indicates peaks from a phase other than binessite.

in this electrolyte was from +0.4 to $-0.4 \mathrm{~V}$ v $\mathrm{Hg} / \mathrm{HgO}$. These experiments were conducted using an EGdG Princeton Applicd Research M362 scanning potentostat comected wh LabView data acquisition software,

\section{Restit and Discission}

Material stucture-Figue 5 conthins the XRD pattens from the materials produced in this work. Essentally, the manganese dioxide phase bimesste predominated irespective of whether ultrasonication was used. There is some evidence for other phases in the paiten of the ulrasonicaled sample (abeled with "In Fig. 5). These have been identifed as cither a-MnO (cryptomelane) or $\mathrm{B}-\mathrm{MnO}_{2}$ (pyrolusite). The presence of these impurity phases weas in some ways to be expected, particularly given the lemplating effect of $\mathrm{K}^{+}$ jons in the formation of birnessite and $\alpha-\mathrm{MnO}_{2},{ }^{21}$ and the fact that $\mathrm{B}_{\mathrm{N}} \mathrm{MnO}_{2}$ is the themodymucally stable variety of manganese dioxide formed hydrothemally at dovated temperatures, which may have been induced with ultrasonication.

Bmessite possesses a layered structure, as shown in Fig. $6 a^{23}$ with forelgn motal tons and water in the interayor region. Crystallographically, it has wen reported to have a wide range of symmemes, induding hexagonal $u_{4}=5.82 \AA$ and $c_{0}=14.62 \AA{ }^{2 A} a_{0}$ $=2.84 \AA$ and $\left.c_{0}=7.27 \AA-5\right)$ orthothombic $a_{0}=8.54 \AA$, bo $=15.39 \AA$, and $\left.c_{0}=14.26 \AA^{26}\right)$, and monodinic $\left(a_{0}=5.149 \mathrm{~A}\right.$, $b_{0}=2.843 \AA, c_{0}=7.176 \AA$, and $\beta=100.76^{\circ} 27$, which is a refiection of the level of disorder that can be induced in this structure. In this study, we have successfully indexed our patterns using a hexagonal unit col with dimensions $i_{0}=2.86 \AA$ and $c_{0}=7.32 \AA$ for the control material and $c_{0}=2.87 \AA$ and $c_{0}=7.28 \AA$ for the ulrasonicated sample. This indicates a larger intcrayer spacing for the control material, potentially as a result of the inclusion of more $\mathrm{K}^{+}$ions, or moro nkely the greater degree of disorder within the controt material structure. To guantify this, the Scherer equation ${ }^{2}$ has been used to calculate crystallte sizes. For the $100 / 101$ podks at $-37^{\circ} 29$, whoh cssentidly represents crystulinity withm the layers, the crystallite size for the control material was 8.6 nu compared to $14.1 \mathrm{~mm}$ for the wirasonicated material. For the 002 peak at $\sim 24^{\circ} 29$, which ropresents the crystallinty between the laycrs, the crystallite size was $9.4 \mathrm{~nm}$ for the control material and $8.9 \mathrm{~nm}$ for (a)

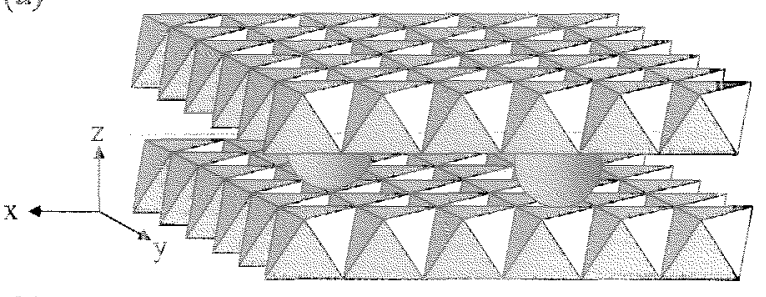

(W)

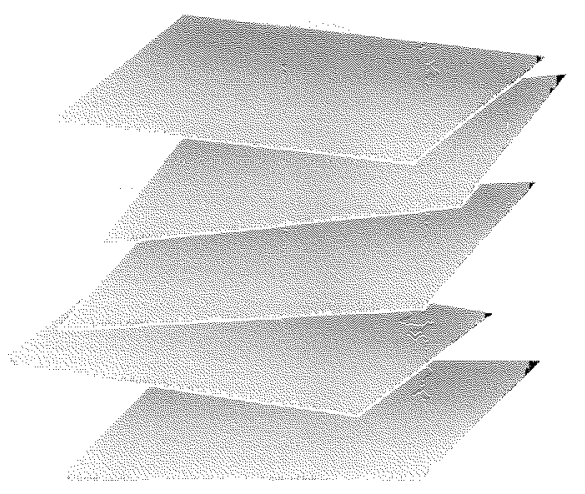

Figure 6. (a) Structure of bincssite showing interlayer water and foreign cations. (b) Schematic of the turbostratic disotdet of the binessite structure in the c-direction.

the ultrasonicated material. Therefore, while the crystallite size between the layers is relatively constant, ultrasonication appears to have a slight effect on crystallization within the layers. Overall, these crystallite sizes are quite small, indicating a very disordered material, one that is potencially suibble for use in a supercapacitor electrode. The level of disorder is particularly pronounced between the layers, nost likcly due to the twbostratio nature of the layered material, and manganese dioxide in parteuar (Fig. 60 ) ${ }^{29}$

Worphology.-Representative miorographs of the control and ultrasoncated manganese dioxide samples aro shown in Fig. 7at and b. From a broad porpective, these materials apparenty have quite similar morphologies, i.e., relatively large agglomerates 5-20 $\mu \mathrm{m}$ in size composed of much smaller particlos. However, upon closer inspection, the morphology of these smaller particles that comprise the larger agglonerates is quite different depending on their synthesis. The smaller particles of the control material appor to be relatively spherical, whereds those of the utrasonicated sample appear to be needlelke. This was confmmed by TEM maging, as shown in Fig, 8 and b. From these figures, the control materiat is doarly based mainly on small, "fluny" Amost amorphous narticles that wo wond sstimate to be < $10 \mathrm{~mm}$. There are also some small noedles present -10 nm wide and up to 100 nm long, but these represent only a minor component of the material. For the ultrasunicated material, however, the needie morphology constutes the major phase present. The needles hero are also slighty lorger, being $-10 \mathrm{~mm}$ wide but $100-200$ nm long.

From the XRD data shown in Fig. 5, we calculated that there were some small differences apparent in the crystalite size of these wo materials. However, fron the TEM images presented in Fig. 8 , apparenty there aro substantial differences in morphology, wh the ultrasonicated material apparenty nore crystalline than the control material. The only logical cxplanation for these observations is that the larger needles present in the ultrasonicated material ure, in fact, agglomerates thenselves, consisting of $\sim 10 \mathrm{~mm}$ phmary particles fused together to form a moh larger needielke morhology. It would therefore seem that the orignal premse of this work, which was to use ultrasonication to break up larger purticles, has in fact led to the formation of larger agglomerates as a recult of the fusion of smaller particles. There is the possibilty that the imprity (minor) 
(a)

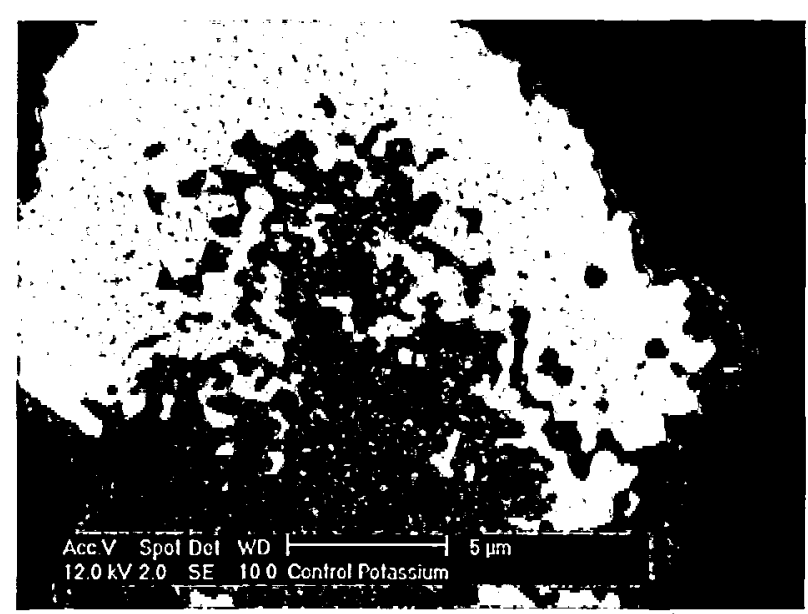

(b)

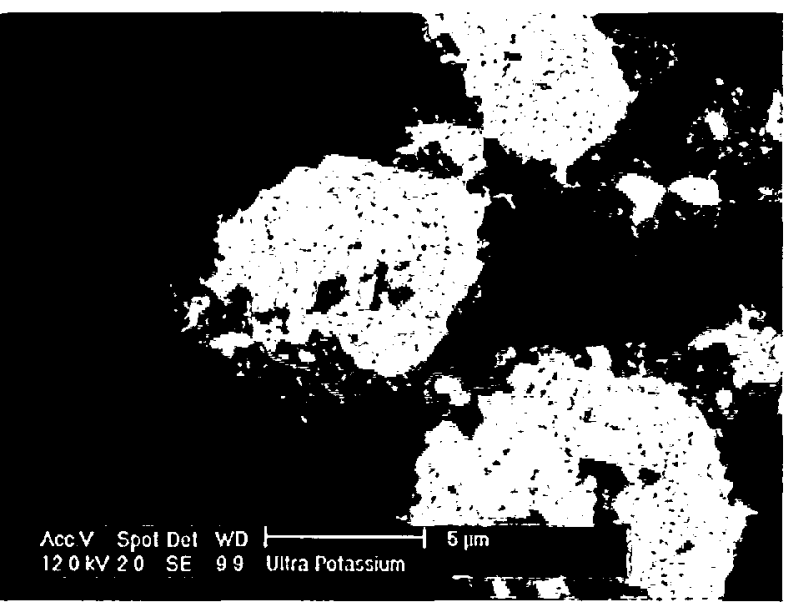

Figure 7. SEM 1 images of the (a) control and (b) ultrasonicated materials.

phases present in the ultrasonicated sample have influenced its morphology compared to the control sample. However, given the extent of our efforts to maintain consistency between the synthesis experiments, the ultrasonication has either microscopically assisted with the nucleation of these phases, or particle fusion itself has given rise to the presence of these impurity phases.

With ultrasonication leading to small particle fusion, we should expect that this would have an effect on the gas adsorption isotherm and hence pore size distribution of the material. Figure $9 a$ and $b$ compares the adsorption isotherms and pore size distributions of the control and ultrasonicated samples, respectively. Clearly, there are significant differences in the adsorption isotherms, with the ultrasonicated material adsorbing on average only $5 \%$ of the gas volume adsorbed by the control material. The calculated BET surface area of the two samples also reflects this with the control material having a surface area of $174 \mathrm{~m}^{2} / \mathrm{g}$, while the ultrasonicated material has a surface area of $10 \mathrm{~m}^{2} / \mathrm{g}$, i.e., $\sim 5 \%$ of the control material surface area. The calculated pore size distribution for these materials also shows that while the distribution of pore sizes is similar, the total volume associated with the respective pore sizes is much smaller for the ultrasonicated material. This does suggest that the building blocks for these materials are similar, as supported by the XRD data, but the particle fusion induced by ultrasonication dramatically reduces the number of pores available to the adsorbate.

Electrochemical performance.- A typical example of the electrochemical performance data collected in this work is shown in Fig. $10 \mathrm{a}$. The voltammograms for these manganese dioxide samples are typical of data collected on the birnessite phase in that they exhibit contributions to the total capacitance from both nonfaradaic and (a)

(b)
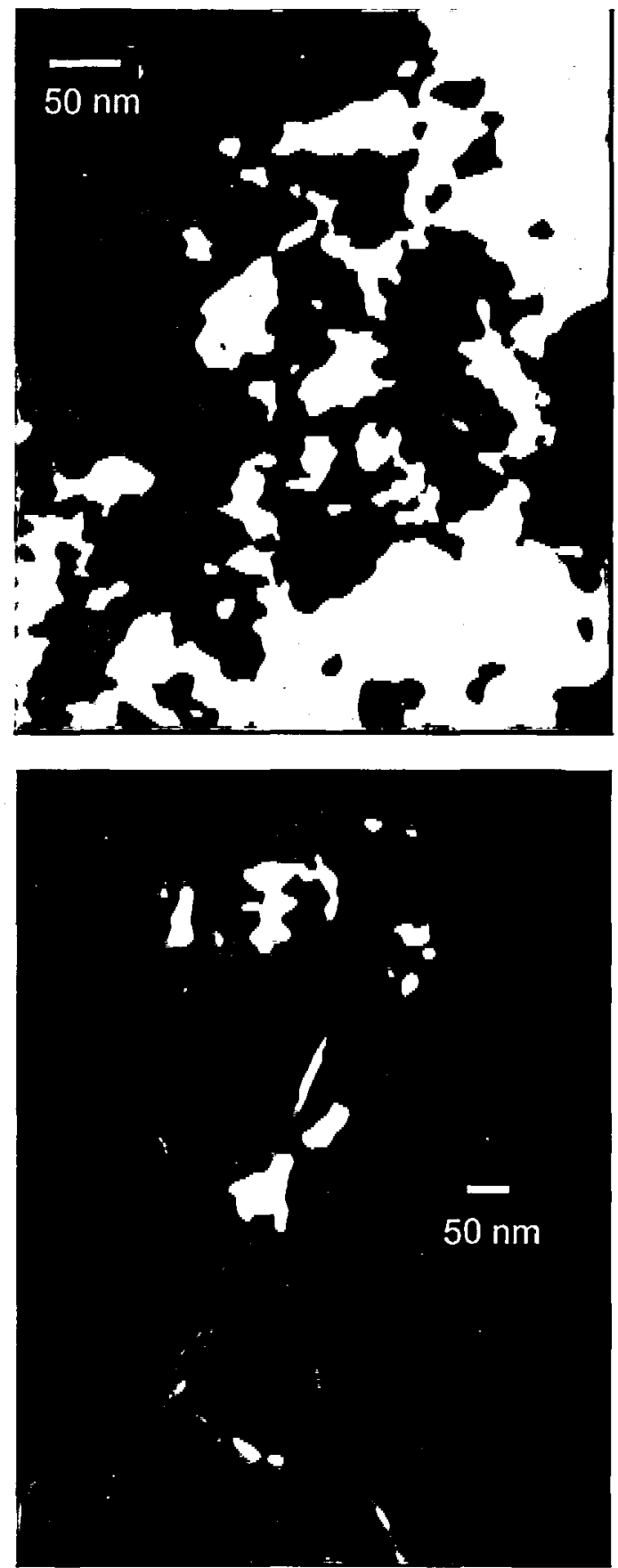

Figure 8. (Color online) TEM images of the (a) control and (b) ultrasonicated materials.

faradaic processes. The contribution of the minority phases present in the ultrasonicated sample toward the total capacitance is difficult to estimate because it is dependent on the surface area and the porosity of these phases (which may be very different from the birnessite), as well as their intrinsic electrochemical activity, which may also be very different.

Another general feature of these voltammograms is their apparent distortion from the expected "box" shape, which is, of course, due to electrode series resistance. There are several recent reports in the literature where the capacitance values of thin films of manganese dioxide $(<10 \mu \mathrm{m})$ have been reported. ${ }^{30}$ The advantages of thin films include a lower series resistance due to shorter transport paths and greater access of the electrolyte to the active surface of 
(n)
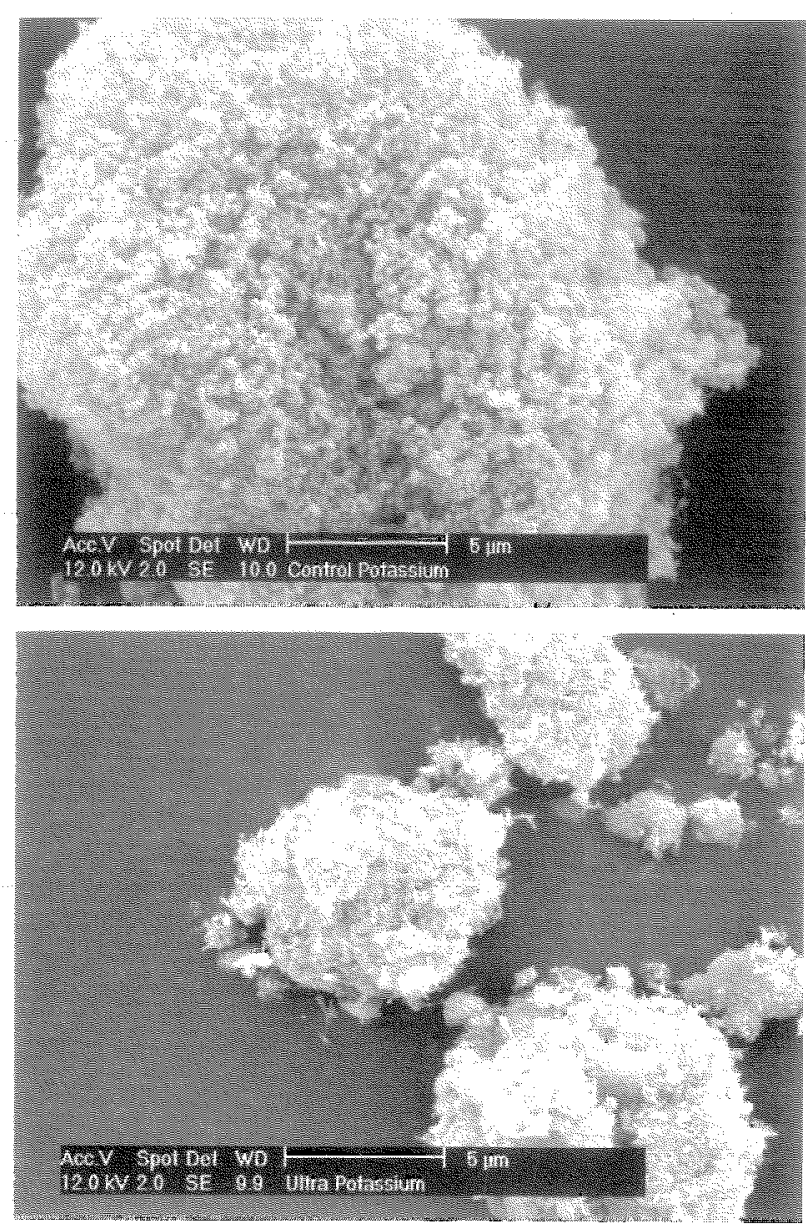

Nigure \%. SEM induges of the (a) control and b) utrusonicated materials.

phases presen in the ultrasonicated sample have influenced its morwhology compared to the control sanple. Howevor, given the extent of our efforts to maintain consistency between the synthesis experiments, the ultrasonication has either microscopically assisted with the mucleation of these phases, or particle fusion itsel has given rise to the presence of those impurity pluases.

Wh ulrasonication loading to snall particle tusion, we should expect that this would have un effect on the gas adsorption isotherm wad hence pore size distribution of the material. Figure ga and $b$ compares the adsorption isotherns and pure size distributions of the control and utrasonicated samples, respectivdy. Clearly, there are Signifint differences in the adsortion isoherns, with the ultrasonicated matcrit adsorbing on average only $5 \%$ of the gas volume udrombel by the control materal. The calenlated BET surface aroa of the two samples also refocts this with the control material having a surtace area of $174 \mathrm{~m}^{2} / \mathrm{g}$, while the lintrasonicated material has a surface area of $10 \mathrm{~m}^{2} / \mathrm{g}$, i.e., $\sim 5 \%$ of the control matcrial surface area. The calculated pore size distribution for these materials also Shows that while the uistribution of pore sizes is similar, the total volume associated with the respective pore sizes is much smaller for tho ultrasonicated material. This does suggest that the bulding blocks for these materials are similar, as supportel by the XRD data, but the particie fusion induced by utmasonication dramatically reances the number of pores available to the sadsorbate.

Electrochenical performance-A typical example of the electrochemical performance data collected in this work shown in Fig. 10a. The voltammograms for these manganese dioxide samplos are typioal of dati collected on the birnessito phase in that hey exhbit contributions to the total capaciance from both nontaradaic and
(3)

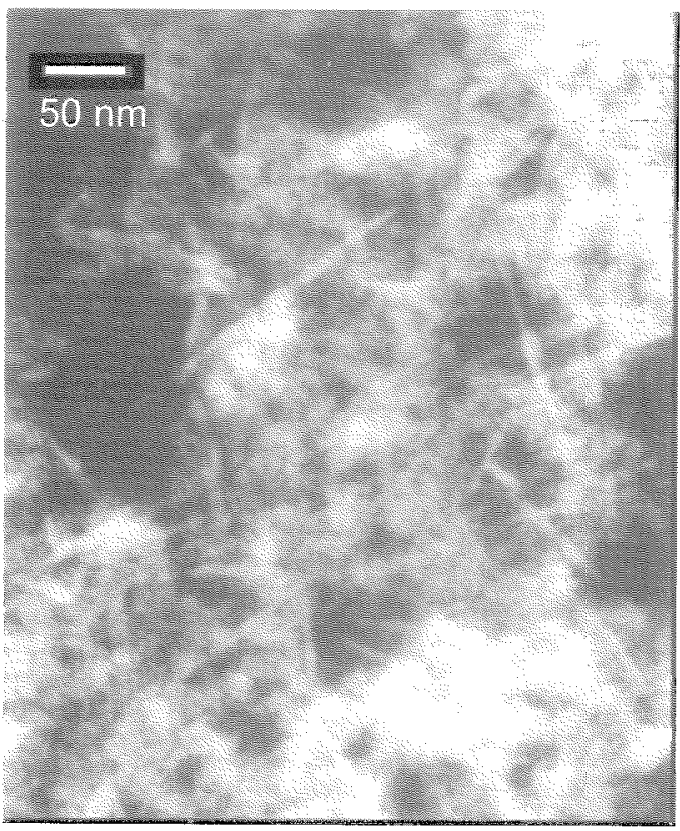

(b)

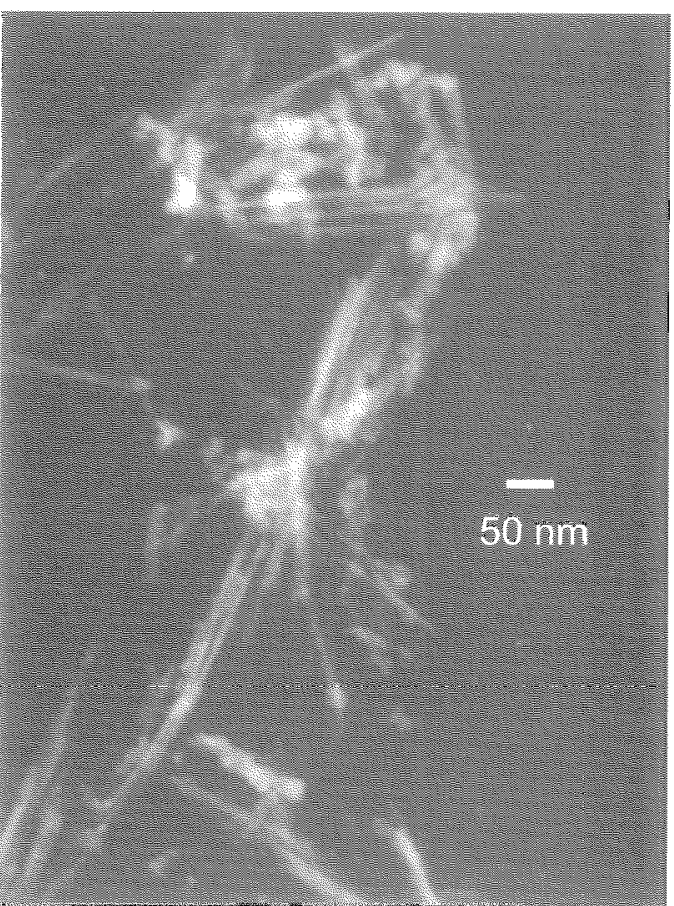

Figurs 8. (Color online) TEM inages of the (a) control und (b) witrasonicated materials

faradaic processes. The contribution of the minority phases present in the ultrasonicated sample toward the toul capactince is difficult 10 estimate because it is dependent on the surfuce aro and the porosity of these phases (which may be very differen from the binessite), as well as their intrisic electrochemical activity, which may ulso be very diferent.

Another general feature of these voltammograms is their apparent distotun from the expected "box" shape, which is, of course, dve to electrode series resistanee. There are several rocont reports in the literature where the capretance values of hin flins of manganese dioxide ( $<10$ wn) have been reportad ${ }^{30}$ Tha advantages of thin fins nolude a lowd series resistance due to shorter masport paths and greater access of the electrolyte to the active surface of 

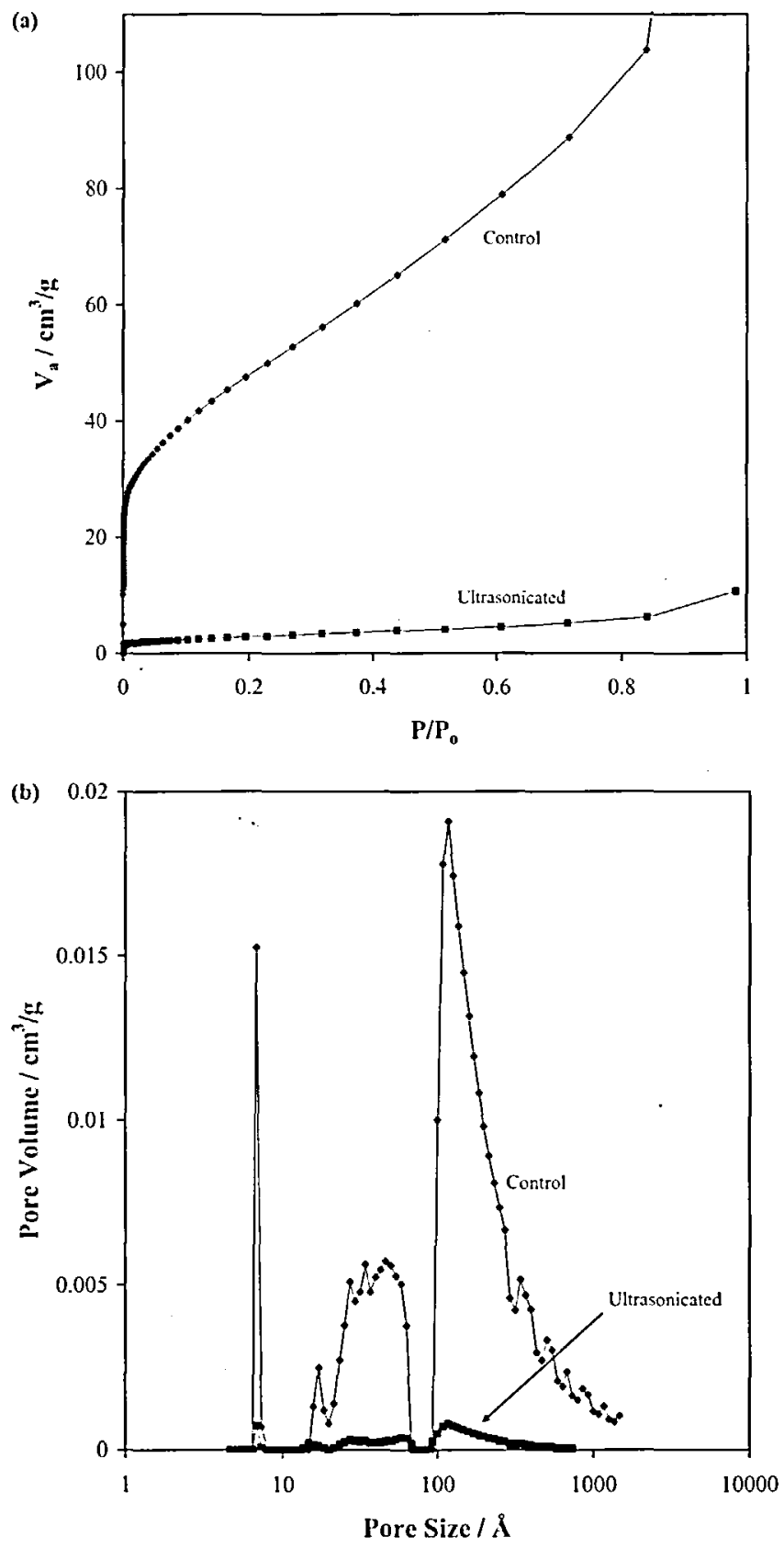

Figure 9. (a) Gas adsorption isotherm and (b) pore size distribution comparison for the control and ultrasonicated materials.

manganese dioxide. However, the main disadvantage is in preparation and processing, which can be complex. Nevertheless, for the relatively thick electrodes used here $(\sim 150 \mu \mathrm{m})$, series resistance is apparently an issue. This is somerwhat compounded by the use of the birnessite phase of manganese dioxide, which has a relatively low intrinsic conductivity, ${ }^{31}$ despite the use of an excess of graphite conductor in the electrode.

Performance-wise, the control material also clearly outperforms the ultrasonicated sample, as shown in Fig. 10b, which presents capacitance vs cycle number for the two types of electrodes. As has been seen before, ${ }^{21}$ the capacitance of the control birnessite sample fades with cycling, most likely due to the contributions made by irreversible faradaic charge transfer. The birnessite phase of manganese dioxide has been shown to initially undergo reversible homogeneous reduction in alkaline electrolytes over a limited compositional range, ${ }^{31}$ i.e.
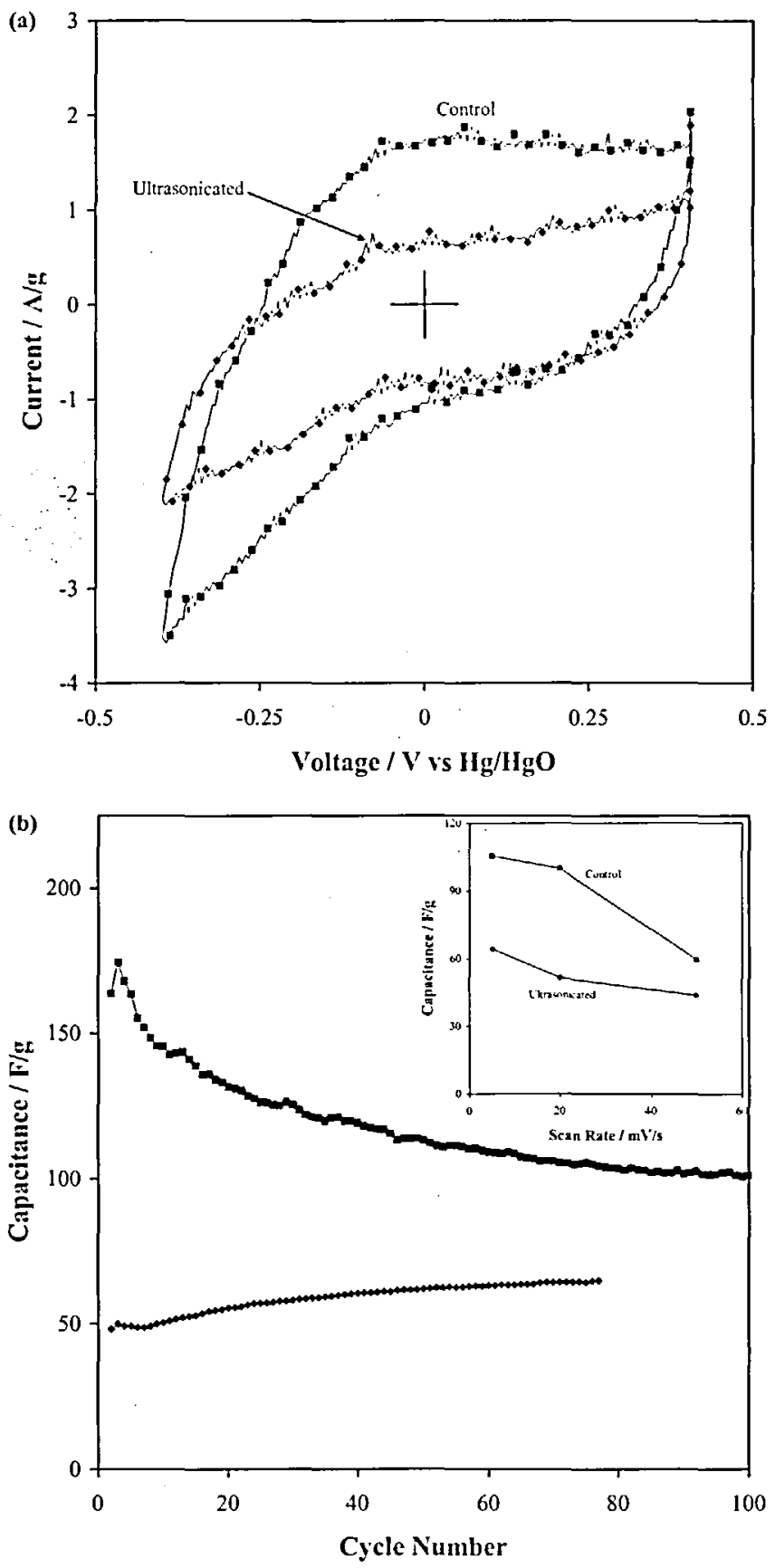

Figure 10. (a) Sample voltammograms (10:1 SFG6: $\mathrm{MnO}_{2}, 9 \mathrm{M} \mathrm{KOH}$ electrolyte, $5 \mathrm{mV} / \mathrm{s}$ ) and (b) the corresponding electrochemical performance data for the control and ultrasonicated materials. Inset: Comparative performance at different scan rates.

$$
\mathrm{MnO}_{2}+\Delta \mathrm{H}_{2} \mathrm{O}+\Delta \mathrm{e}^{-} \rightarrow \mathrm{MnOOH}_{\lrcorner}+\Delta \mathrm{OH}^{-}
$$

where $\Delta$ represents the extent of homogeneous reduction, which for the birnessite phase is at most 0.30 . Upon further reduction, the birnessite structure progressively collapses to form $\mathrm{Mn}_{3} \mathrm{O}_{4}$, which cannot be further reduced or oxidized, ${ }^{31}$ i.e.

$$
3 \mathrm{MnOOH}_{\mathrm{J}}+(2-\Delta) \mathrm{H}_{2} \mathrm{O}+(4-\Delta) \mathrm{e}^{-} \rightarrow \mathrm{Mn}_{3} \mathrm{O}_{4}+(4-\Delta) \mathrm{OH}^{-}
$$

The impurity phases present in the ultrasonicated sample may have also contributed to its decreased level of performance; however, the extent of their impact on performance is difficult to estimate given 
that the amount of the species present is unknown, as are their surface area and intrinsic electrochemical activity.

The effects of the scan rate on electrode performance (capacitance after 70 cycles) are also shown in Fig. $10 \mathrm{~b}$ (inset). As expected, the capacitance decreases with increasing scan rate, which is an indicator of the kinetic limitations associated with both faradaic and nonfaradaic charge storage because in the former the redox reactions (such as proton and electron insertion ${ }^{32.33}$ and phase transformations ${ }^{34}$ ) cannot keep pace with the sweep rate, while in the latter the morphological changes the material undergoes during discharge can limit electrolyte access to the manganese dioxide surface. ${ }^{35}$ As a final point, while the control material outperforms the ultrasonicated sample, it is not to the full extent expected based on the relative surface areas of the materials. This does suggest that the pore size distribution is important for determining the overall performance, with the likely effect being that mass transport of electrolyte in micropores $(<2 \mathrm{~nm}$ in size) may cause its associated surface area to not be available for charge storage. This is particularly important when faradaic processes consume water in the electrolyte within the micropores, meaning that species from the bulk electrolyte must be transported into the pores to replenish what has been consumed and also to avoid the possibility that the electrolyte might precipitate within the pore. Clearly, with larger pores, the mass transport of the electrolyte would be more effective. Nevertheless, it is clear that the use of ultrasonication during synthesis diminishes electrochemical performance, as a result of particle fusion.

\section{Conclusion}

In this work, ultrasonication has been used in the synthesis of manganese dioxide to examine its impact on sample structure, morphology, and electrochemical performance. The key findings of this work are as follows:

1. From the XRD data, it was determined that layered birnessite was the predominant phase produced. Small impurities of the tunnel structures $\alpha-\mathrm{MnO}_{2}$ (cryptomelane) and $\beta-\mathrm{MnO}_{2}$ (pyrolusite) were present in the ultrasonicated material. The crystallite size of these materials was similar ( $8.6 \mathrm{vs} 14.1 \mathrm{~nm}$ within the layers, and $9.4 \mathrm{vs}$ $8.9 \mathrm{~nm}$ between the layers for the control and ultrasonicated samples, respectively), but with a slight trend toward increased crystallinity within the birnessite layers when ultrasonication was used.

2. Material morphologies were very different, with the control material possessing an almost amorphous, fluffy morphology $(\sim 10 \mathrm{~nm}$ diameter roughly spherical particles), while the ultrasonicated sample consisted of needles $\sim 10 \mathrm{~nm}$ wide and $100-200 \mathrm{~nm}$ long).

3. Given the small differences in crystallite size, it was concluded that particle fusion had occurred to form the much larger needlelike particles.

4. An effect of particle fusion was to lower the BET surface area, i.e., $170 \mathrm{~m}^{2} / \mathrm{g}$ for the control material vs $10 \mathrm{~m}^{2} / \mathrm{g}$ or the ultrasonicated sample. The total pore volume. was also decreased; however, the range of pore sizes present did not change.

5 . With such a decrease in surface area, the electrochemical performance of the ultrasonicated material decreased compared to the control material, e.g., 64 vs $106 \mathrm{~F} / \mathrm{g}$, respectively. This drop in performance was, however, not consistent with the absolute decrease in surface area observed, prompting speculation that certain pore sizes are not available for use.

\section{Acknowledgments}

The authors acknowledge the contributions made by Dave Phelan and Jenny Zobec from the University of Newcastle Electron Microscopy-X-Ray Facility. B.C.J. would also like to acknowledge the receipt of a joint CSIRO-University of Newcastle postgraduate scholarship.

University of Newcastle assisted in meeting the publication costs of this article.

\section{References}

I. N. S. Lewis, Scientific Challenges in Strstainable Energy Tcchmology, in 208th Meeting of the Electrochemical Society. Los Angeles, CA (2005).

2. D. Ragone, in Proceedings of the Society of Automotive Engineers Conference. Detroit, MII (1968).

3. hup://en.wikipedia.org/wiki/Ragone_plot, last aceessed 2009.

4. P. Simon and Y. Gogotsi, Nature Mater, 7, 845 (2008).

5. B. E. Conway, Electrochemical Supercopacitors: Scientific Fundamentals and Technological Applications, Kluwer-Plenum, New York (1999).

6. K. Naoi and P. Simon, Electrochem. Soc. Literface, 17(1), 34 (2008).

7. D. Bélanger, T. Brousse, and J. W. Long, Elcctrochem. Soc. Interface, 17(1), 49 (2008).

8. W. Feitknecht and W. Mari, Hell: Chim. Acta, 28, 129 (1945); W. Feitknecht and W. Marti, Helt: Chim. Acra, 28, 149 (1945); O. Glemser, G. Gattow, and H. Meisiek, Z Anorg. Allg. Chem., 309, 1 (1961); Y. F. Yuo and H. S. Wroblowa, J. Electroanal. Chem. Interfacial Electrochem., 223, 107 (1987); R. M. McKenzie, Miner. Mag. 38, 493 (1971); J. B. Fernandes, B. D. Desai, and V. N. Kamat Dalal, J. Power Sources, 15, 209 (1985); E. Narita and T. Okabe, Bull. Chem. Soc. Jpm., 53. 525 (1980); M. H. Rossouw, D. C. Liles, and M. M. Thackeray, Prog. Batteries Battery Mater., 15, 8 (1996).

9. T. J. Mason and J. P. Lorimer, Applied Sonochemistry: The Uses of Power Ulirasound in Chemistry and Processing, Wiley-VCH, New York (2002).

10. F. R. Young, Cavitation, McGraw-Hill, U.K. (1989).

11. T. G. Leighton, The Acoustic Bubble, Academic, London (1994).

12. Sonochemistry and Sonoluminescence, L. A. Crum, T. J. Mason, J. L. Reisse, and K. S. Suslick, Editors, Kluwer, Dordrecht (1999).

13. E. W. Flosdorf and L. A. Chambers, J. Am. Chem. Soc., 55, 3051 (1933).

14. J. P. Lorimer, T. J. Mason, T. C. Cuthbert, and E. A. Brookfield. Ultrason. Sonochem., 2, S55 (1995).

15. W. Lauterborn and W. Hentschell, Ulirasmics, 23, 260 (1985).

16. B. Pugin and A. T. Tumer, in Adrances in Sonochemistn;, Vol. I, T. J. MIason, Editor, p. 81, JAI, London (1990); K. S. Suslick and D. Docktycz, in Adrances in Sonochemistry; Vol. 1, T. J. Mason, Editor, p. 187, JAI, London (1990).

17. J. W. Long, R. M. Stroud, and D. R. Rolison, J. Non-Cryst. Solids, 285, 288 (2001).

18. CRC Handbook of Physic and Chemistry, D. R. Lide, Editor, CRC Press, Boston (1991).

19. S. Brunauer, P. H. Emmett, and E. Teller, J. Am. Chem. Soc., 60, 309 (1938).

20. P. A. Webb and C. Or, Analytical Methods in Fine Particle Technology, Micromeritics Corporation, Allanta, GA (1997).

21. B. C. Jones, A. F. Hollenkamp, and S. W. Donne, J. Power Sources, 195, 367 (2010).

22. M. Pourbaix, Allas of Electrochemical Equilibria in Aqucous Solutions, Pergamon, London (1966).

23. V. M. Bums, R. G. Burns, and W. K. Zwicker, in Proceedings of the $\mathrm{MnO}_{2} \mathrm{Sym}$ positm, Vol. 1, A. Kozawa and R. J. Brodd, Editors, p. 288 (1975); R. G. Burns and V. M. Bums, in Proceedings of the $\mathrm{MnO}_{2}$ Symposium, Vol. 1, A. Kozawa and R. J. Brodd, Editors, p. 306 (1975); R. G. Burns and V. M. Burns, in Proceedings of the $\mathrm{MnO}_{2}$ Symposium, Vol. 2, B. Schumm, H. M1. Joscph, and A. Kozawa, Editors, p. $97(1980)$.

24. W. Buser, P. Graf, and W. Feitknecht, Hel: Chim. Acta, 37, 2322 (1954).

25. R. Giovanoli, E. Stähli, and W. Feitknecht, Heh: Chim. Acta, 53, 453 (1970).

26. R. Giovanoli, E. Stähli, and W. Feitknecht, Helr: Chim. Acta, 53, 209 (1970).

27. J. E. Post and D. R. Veblen. Am. Mineral., 75, 477 (1990).

28. A. R. West, Solid State Chemistry and its Applications, John Wiley \& Sons, New York (1984)

29. R. Giovanoli, in Geology and Geochemistry of Manganese, Vol. 1, I. M. Varentsov and G. Grasselly, Editors, p. 159, Akademiai Keadó, Budapest (1980).

30. S. C. Pang, M. A. Anderson, and T. W. Chapman. J. Electrochem. Soc., 147, 414 (2000).

31. S. W. Donne, Ph.D. Thesis, University of Neweastls, Australia (1996).

32. A. Kozawa and J. F. Yeager, J. Electrochem. Soc., 112, 959 (1965).

33. Z. Hong, C. Zhenhai, and X. Xi, J. Electrochem. Soc., 136. 2771 (1989).

34. S. W. Donne, G. A. Lawrance, and D. A. J. Swinkels, J. Electrochem. Soc., 14, 2961 (1997).

35. A. P. Malloy and S. W. Donne, J. Electrochem. Soc., 155, A817 (2008). 